Website: ijetms.in Issue: 7 Volume No.4 November -2020 DOI: 10.46647/ijetms.2020.v04i07.002

\title{
Low Power and Area Efficient 4-2 Compressor for Signal Processing Applications
}

\author{
S Mohan Das ${ }^{1}$, M Ganesh Kumar $^{2}$, G Shireesha ${ }^{3}$ \\ ${ }^{1}$ Assistant Professor, SVR Engineering College, Nandyal \\ ${ }^{2}$ Assistant Professor, SVR Engineering College, Nandyal \\ ${ }^{3} P G$ student, SVR Engineering College, Nandyal \\ ${ }^{1}$ mohantech418@gmail.com \\ 2mgani411@gmail.com \\ ${ }^{3}$ shireeshagopireddy82@gmail.com
}

\begin{abstract}
In this paper, two performance metrics power and delay are estimated for various XOR-XNOR circuits and Multiplexer for designing 4-2 compressor. The main objective is to design an energy efficient compressor for computing applications in FIR filter. The simulations for the designed circuits performed in cadence virtuoso tool with $45 \mathrm{~nm}$ CMOS technology at a supply voltage of 0.9 Volts. The proposed 4-2 compressors consist of six blocks out of which two XOR-XNOR blocks and four MUX blocks. The average power, delay and energy consumed by the proposed compressor which is based on $5 \mathrm{~T}$ XOR-XNOR and GDIMUX design is $\mathbf{8 5 . 7 2}$ $\mathrm{nW}, 62.53 \mathrm{pS}$ and $5.36 \mathrm{aJ}$ respectively.
\end{abstract}

Keywords: XOR-XNOR module, MUX, GDI, 4-2 Compressor, Delay and Energy.

\section{INTRODUCTION}

In a microprocessor or a digital signal processor (DSP), data path plays a prominent role since performance metrics like the die-area, speed of operation, power dissipation etc., depend directly on the efficiency of data-path [1]. In computer arithmetic and high performance system, such as FIR filters, the multipliers and dividers are the most important part. In most cases, the multiplier consists of three stages. The second stage (i.e. reduction of partial products) is most important stage.
This stage is only accountable for the power and delay. So as to accumulate partial products, compressors are used at this stage to reduce the partial products and critical path [2-3]. Power and delay are the two performance metrics which comprehensively decide the energy metric of the system in low power application and high performance computing in IoT applications. [4-5].

Leakage power dissipation is eventually becoming comparable to dynamic power dissipation in many high performance designs when the design is at near threshold computing applications. The very large level of integration results in complication of heat removal; this in turn increases the cost of cooling and packaging [6].

In this paper, various XOR-XNOR gates with reduced transistors are proposed to design an energy efficient 4-2 Compressor for computing applications. The rest of the paper is organized as follows: Section 2 describes literature survey and proposed circuit implementation is introduced in section 3. Section 4 presents the result and discussion. Section 5 draws the conclusion.

\section{LITERATURE REVIEW}

G. Venkata Rao et. al., proposed [7] a 


\title{
International Journal of Engineering Technology and Management Sciences
}

\author{
Website: ijetms.in Issue: 7 Volume No.4 November -2020 DOI: \\ 10.46647/ijetms.2020.v04i07.002
}

dynamic comparator with low power, high speed and low offset voltage has been proposed in order to make the ADC efficient. Design is based on pre amplifier re- generation circuit and a latch. The result of the proposed design shows that the circuits are more optimized in terms of delay, power consumption, and power delay product at the cost of reduced voltage swing.

The Level shifters are assembling circuits. To assemble "Multiple functional circuit blocks" multiple LSs are required, commonly for "Low voltage to high voltage translation" LSs are employed and "High to voltage to low translation" inverters are adequate at the cost of additional circuitry [8]. The author presented a "Novel high performance Dynamic Voltage Level Shifter" to act as assembling circuit between multiple functional circuit blocks. The result reveals static power of 4.6 Nano Watts.

Circuit Power consumption, area and delay are the majority important design issues being addressed by many algorithms. Among different types of Delay and power reduction techniques "Clustered voltage scaling" techniques is the best way, it patricians the design into multiple voltage blocks, "High speed sensitive voltage blocks" are biased with higher VDD to increase the speed performance and "Low speed sensitive voltage blocks" may be biased with lower VDD to decrease power consumption [9-10].

Multi voltage clustered structures are the fundamental and imperative power lowering techniques; utilize voltage Level shifter (LS) circuits to intercommunicate "Multiple voltage circuit blocks" to shrink power at core or circuit modules. The LS may deem as delay and power expenditure when its individual contributions are high. The developed Diode current limiter LS have implemented in $130 \mathrm{~nm}$ technology, which minimizes power and delay at the cost of area overhead [11].

Optimization at the logic level can be achieved by minimizing the logic by its equivalent and Boolean based logic reduction, logic level power down alike. Logic level power down controls the logic switching activity at the expense of additional circuits. Optimization depends on the circuit complexity and other factors at this level. Upto $50 \%$ power consumption can be possible with these methods. Pass transistor based MOS Switch Integrated Ultra Low Power 1-bit full adder (MOSSI-ULP) is the design by Vijaya kumar and Reeba Korah for which the biasing techniques are applied to restore the full swing [12].

Y. Amar Babu et al., proposed [13] a novel area and power efficient on chip communication architectures for image encryption and decryption using single soft processor (Micro Blaze). Proposed System On Chip explores On chip Communication architectures features to efficiently implement the application. The SoC offers scalability and guarantees on the timing behaviour when communicating data between various processing and storage elements. Proposed $\mathrm{SoC}$ has been implemented on Spartan6 FPGA and evaluated at 83.33 MHz. It has occupied only $19 \%$ of resources available on target FPGA, consumes very low power $68 \mathrm{~mW}, 15 \%$ of conventional architectures. The proposed on chip communication architectures compared with device utilization on FPGA and power consumed. 


\title{
International Journal of Engineering Technology and Management Sciences
}

\author{
Website: ijetms.in Issue: 7 Volume No.4 November -2020 DOI: \\ 10.46647/ijetms.2020.v04i07.002
}

Various energy efficient arithmetic circuits at low supply voltages and ultralow supply voltages have been proposed by various authors namely adder, multipliers, subtractor, divider and level shifter in the literature [14-18].

From the literature it has been clear that power and delay are the two performance metrics which can decide the energy metric of a digital circuit in low power applications.

\section{Proposed Method}

Compressor is extensively employed in realization of multipliers to reduce the partial products. The 4-2 compressor has five inputs and three outputs and which is shown in below figure 1.The five inputs are compressed into three outputs, where $\mathrm{X} 1, \mathrm{X} 2, \mathrm{X} 3, \mathrm{X} 4, \mathrm{C}$ in are the inputs and Cout, Carry, Sum are the outputs.

Here output Sum and input X1, X2, $\mathrm{X} 3, \mathrm{X} 4$ has same weight. The proposed 4-2 compressors consist of six blocks out of which two XOR-XNOR blocks and four MUX blocks which are shown in figure 2 .

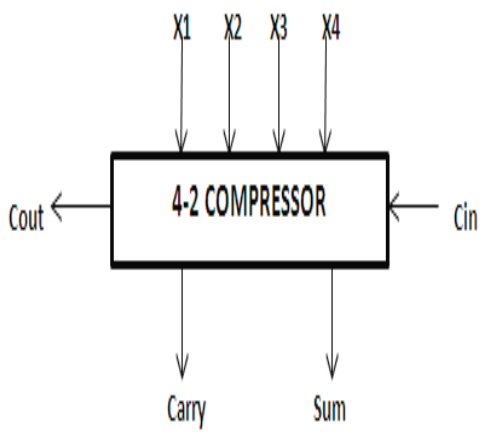

Fig.1. Compressor block diagram
The circuit diagram of CMOS 5T XOR-XNOR module, GDIMUX and proposed 4-2 compressor were shown in figures3, 4and 5 respectively. Figure 6 shows the post lay out waveform of proposed 4-2 Compressor.

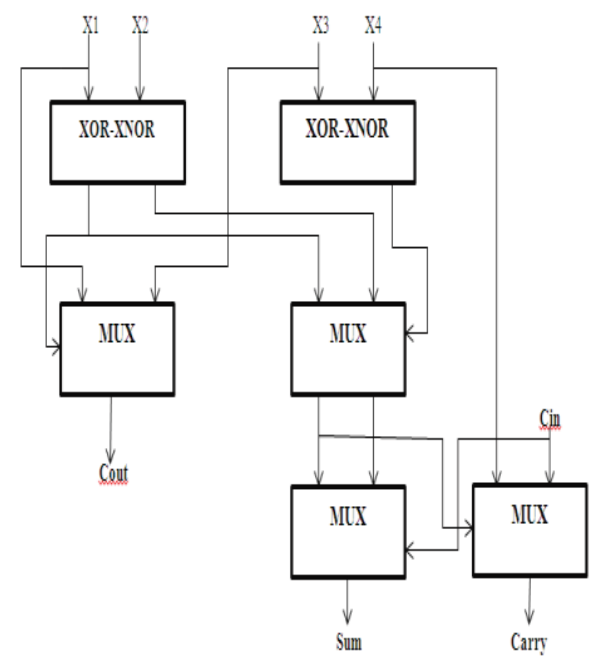

Fig.2. Logical decomposition of 4-2 compressor

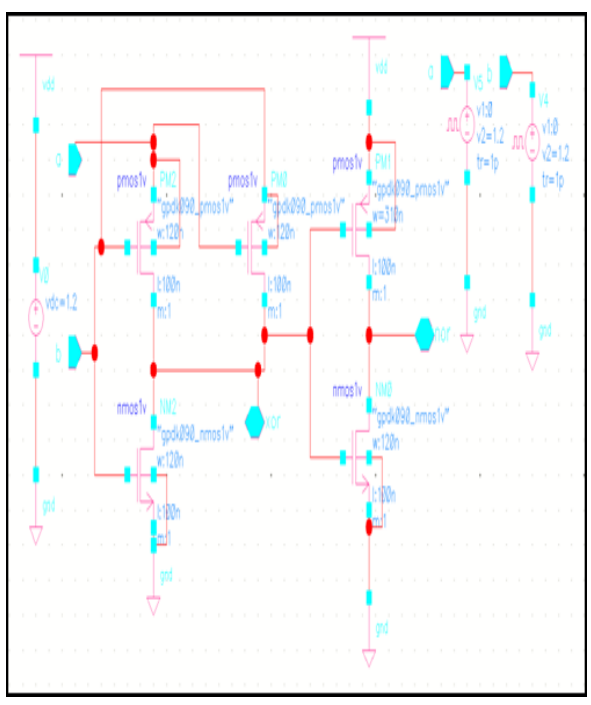

Fig.3.Circuit diagram of 5T XOR-XNOR 


\section{International Journal of Engineering Technology and Management Sciences}

Website: ijetms.in Issue: 7 Volume No.4 November - 2020 DOI:

10.46647/ijetms.2020.v04i07.002

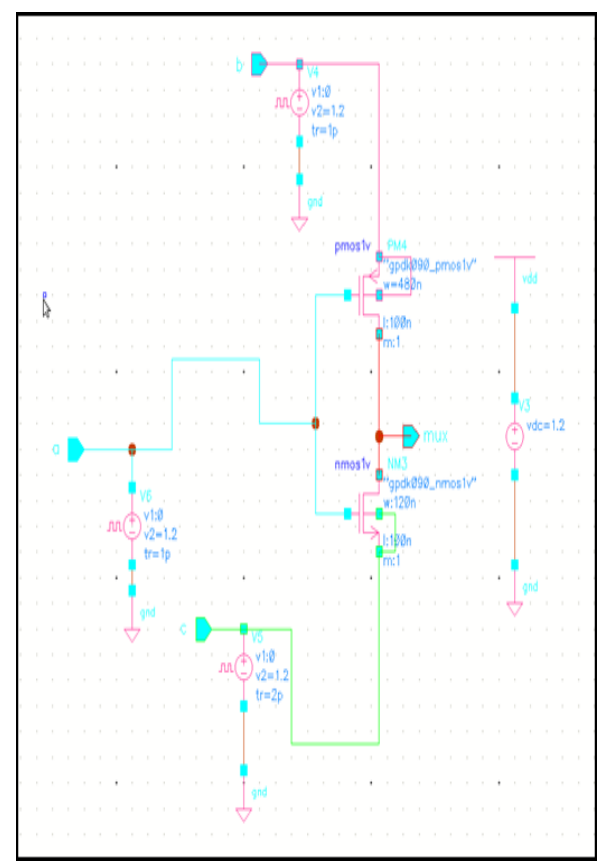

Fig.4.Circuit diagram of GDI MUX

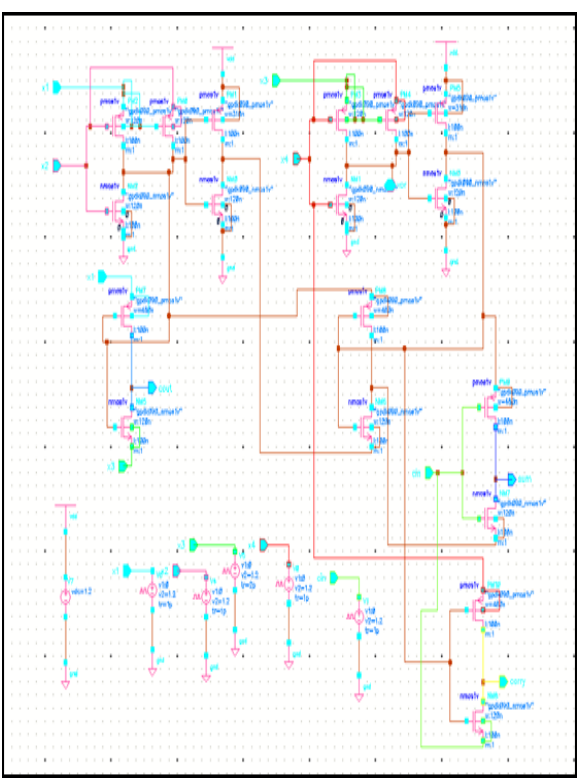

Fig.5.Circuit diagram of proposed 4-2 Compressor

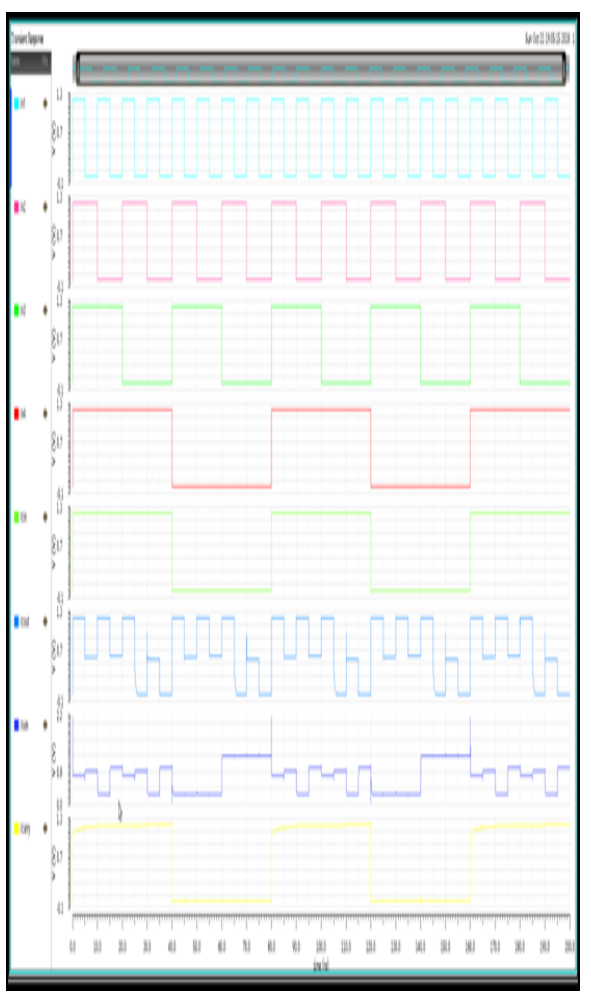

Fig.6.Post lay out waveform of proposed 42 Compressor

IV. RESUlTS AND DISCUSSION

Initially the conventional CMOS XOR-XNOR gate and MUX logic is simulated at $45 \mathrm{~nm}$ technology as they are the basic block for any digital systems, then the simulation has been carried out for proposed 4-2 compressor which employs 5T XOR-XNOR gate and GDIMUX logic. Based on the three different XOR-XNOR gates and Mux a 4-2 compressor was proposed.

The simulation results of proposed design along with conventional and existing were shown in table 1. From the results it has been clear that the propagation delay and energy for the proposed design is less both in case of 


\title{
International Journal of Engineering Technology and Management Sciences
}

\author{
Website: ijetms.in Issue: 7 Volume No.4 November -2020 DOI: \\ 10.46647/ijetms.2020.v04i07.002
}

5T XOR-XNOR gate as well as GDIMUX gate at cost of average power consumption.

Performance metrics of Proposed 4-2 compressor was depicted in figure 7.

TABLE 1.

SIMULATION RESULTS OF VARIOUS CIRCUITS

\begin{tabular}{|c|c|c|c|}
\hline Design & $\begin{array}{c}\text { Average } \\
\text { Total } \\
\text { Power } \\
\text { (nW) }\end{array}$ & $\begin{array}{c}\text { Delay } \\
\text { (ps) }\end{array}$ & $\begin{array}{c}\text { Energy } \\
\text { (aJ) }\end{array}$ \\
\hline $\begin{array}{c}\text { CMOS } \\
\text { XOR- } \\
\text { XNOR }\end{array}$ & 827.6 & 42.1 & 34.841 \\
\hline $\begin{array}{c}\text { 8T XOR- } \\
\text { XNOR }\end{array}$ & 805.2 & 29.5 & 23.753 \\
\hline $\begin{array}{c}\text { 5T XOR- } \\
\text { XNOR }\end{array}$ & 2800 & 4.5 & 12.6 \\
\hline $\begin{array}{c}\text { CMOS } \\
\text { MUX }\end{array}$ & 661.7 & 42 & 27.791 \\
\hline TG MUX & 393.8 & 12.1 & 4.764 \\
\hline GDI MUX & 981.9 & 3.1 & 3.043 \\
\hline $\begin{array}{c}\text { Proposed } \\
\text { 4-2 } \\
\text { compressor }\end{array}$ & 85.72 & 62.53 & 5.36 \\
\hline
\end{tabular}

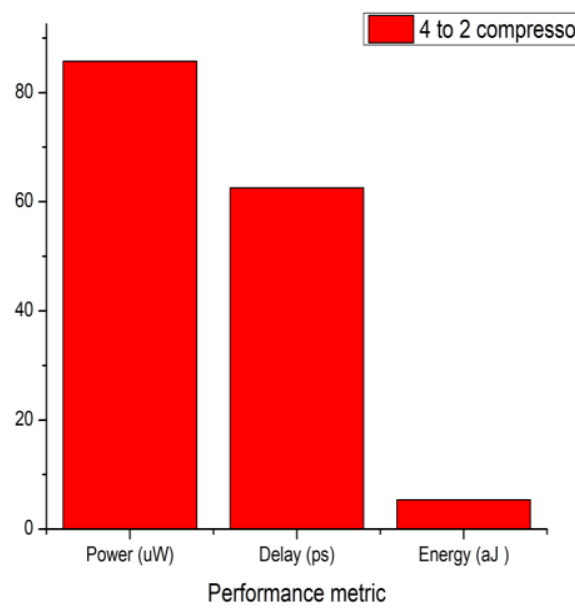

Fig.7. Performance metrics of Proposed 4-2 compressor

\section{CONCLUSIONS}

In this work, an energy efficient 42compressor was designed. The simulations for the existing and the proposed circuits have been carried out by using Cadence Tool at $45 \mathrm{~nm}$ technology.

The proposed design was analyzed with the existing CMOS and 8T XOR$\mathrm{XNOR}$ based compressors. The design is energy efficient with 5TXOR-XNOR module and GDIMUX unit based 4-2 compressor. The average power, delay and energy consumed by the proposed compressor which is based on 5T XORXNOR and GDIMUX design is 85.72 $\mathrm{nW}, 62.53 \mathrm{pS}$ and $5.36 \mathrm{aJ}$ respectively.

The proposed designs perform better than the existing ones in terms of power, delay and power-delay product (energy).

\section{References}

[1] M.Mahaboob Basha, K.Venkata Ramanaiah and P. Ramana Reddy," Design of CMOS full subtractor using $10 \mathrm{~T}$ for object detection application", International Journal of Reasoning-based Intelligent Systems (IJRIS), 2018, Vol.10, No.3/4, pp.286-295.

[2] S. Goel, M. A. Elgamel, M. A. Bayoumi and Y. Hanafy, "Design methodologies for highperformance noise-tolerant XOR-XNOR circuits," in IEEE Transactions on Circuits and Systems I: Regular Papers, vol. 53, no. 4, pp.867-878, April 2006, doi: 10.1109/TCSI.2005.860119.

[3] M.Mahaboob Basha, K. Venkata Ramanaiah and P. Ramana Reddy, "Novel Low Power and High speed array divider in 65 nm Technology" ,International Journal of Advances in Science and Technology, Vol. 6, No. 6, pp.44-56, ISSN: 2229-5216, 2013.

[4] Ganjikunta Ganesh Kumar, Sibghatullah I. Khan and M. Mahaboob Basha, "A HighPerformance Signed-Unsigned Multiplier Using Vedic Mathematics", Journal of Low Power Electronics (JOLPE), 2019, Vol. 15, No. 3, pp.302-308. 


\title{
International Journal of Engineering Technology and Management Sciences
}

\author{
Website: ijetms.in Issue: 7 Volume No.4 November - 2020 DOI: \\ 10.46647/ijetms.2020.v04i07.002
}

[5] S. Gundala, M. M. Basha and S. Vijayakumar, "Double Current Limiter High Performance Voltage Level Shifter for IoT Applications," $2020 \quad 5$ th International Conference on Communication and Electronics Systems (ICCES), COIMBATORE, India, 2020, pp. 285-288, doi: 10.1109/ICCES48766.2020.9137901.

[6] M.Mahaboob Basha, K.Venkata Ramanaiah, P. Ramana Reddy," Design of Near Threshold 10T- Full Subtractor Circuit for Energy Efficient Signal Processing Applications", International Journal of Image, Graphics and Signal Processing(IJIGSP), Vol.9, No.12, pp. 23-29, 2017.DOI: 10.5815/ ijigsp.2017.12.03.

[7] G. Venkata Rao, T. AnjaniVineela, S. Chandrika, J. Ravalika, N. SethuMadhav, E.V.Krishna Rao, "Pre-amplifier latch CMOS comparator using $130 \mathrm{~nm}$ technology for Analog to Digital Converters", International Journal of Advanced Science and Technology, Vol. 2, Issue-05, pp. 1043710441, June 2020.

[8] Srinivasulu Gundala, Venkata K. Ramanaiah, Padmapriya K, "A Novel High Performance Dynamic Voltage Level Shifter", ARPN Journal of Engineering and Applied Sciences, Vol. 10, No. 10, pp. 4424- 4429, June 2015.

[9] Srinivasulu Gundala, Venkata K.Ramanaiah, Padmapriya Kesari, "Nanosecond Delay Level Shifter with Logic level Correction", International Conference on Advances in Electronics, Computers and Communications (ICAECC), 2014.

[10] K. Lakshmi Bhanu Prakash Reddy, Vijayakumar. S, Umasankar. P and G. Hemantha reddy, "High Speed, Low Area Exact Speculative Carry Look Ahead Adder using MGDI Technique",International Journal of Engineering and Advanced Technology, 8(6).5090-5094, (2019).

[11] Srinivasulu Gundala, Kommu Siddhartha Mavovarakumar, Kona Naga Nandini, SravaniGantala, Javisetty Ravi SankarVarma, ChakralaNavya, "Development of Optimized Voltage Level Shifter for Nanoscale Applications", ARPN Journal of Engineering and Applied Sciences, Vol. 15, No. 14, pp. 1552- 1556, July 2020

[12] Vijayakumar, S., Reeba Korah, "Circuit level, 32nm, 1-bit MOSSI-ULP adder: power, PDP and area efficient base cell for unsigned multiplier", IEICE Electronics Expres, 11(7). 1-7, (2014).
[13] Y. Amar Babu, G. M. V. Prasad, "An Area and Power Efficient On Chip Communication Architectures for Image Encryption And Description", International Journal of Research in Engineering and Technology (IJRET), Vol. 3, Issue 5, May 2014.

[14] M.Mahaboob Basha, K. Venkata Ramanaiah, P. Ramana Reddyand B. Lokeshwar Reddy, "An efficient model for design of 64-bit High Speed Parallel Prefix VLSI adder", International Journal of Modern Engineering Research, Vol.3, Issue.5, pp.2626-2630, ISSN:2249-6645, 2013

[15] S HaroonRasheed, S Mohan Das and Gaddam Samba Sivudu, "Design of energy efficient hybrid 1-bit full adder for arithmetic applications", International Journal of Engineering Technology and Management Sciences (IJETMS), Vol. 4 Issue. 5, 2020.

[16] N. F. Afreen, M. M. Basha and S. M. Das, "Design and implementation of area-delaypower efficient CSLA based 32-bit array multiplier," 2017 2nd IEEE International Conference on Recent Trends in Electronics, Information \& Communication Technology (RTEICT), Bangalore, 2017, pp. 1578-1582, doi: 10.1109/RTEICT.2017.8256864.

[17] M. Mahaboob Basha, K. Venkata Ramanaiah and P. Ramana Reddy, " Novel Energy Efficient one bit Full Subtractor at $65 \mathrm{~nm}$ technology," 2015 International Conference on Electrical, Electronics, Signals, Communication and Optimization (EESCO), Visakhapatnam, 2015, pp. 1-5, doi: 10.1109/EESCO.2015.7253873.

[18] Mahammad, F.S., Viswanatham, V.M. "Performance analysis of data compression algorithms for heterogeneous architecture through parallel approach", Journal of Supercomputing 76, 2275-2288 (2020). https://doi.org/10.1007/s11227-018-2478-3. 